\title{
THE IMMEDIATE TREATMENT OF HEAD INJURIES.
}

\author{
By KENNETH L. JAMES, M.S., F.R.C.S. \\ (Assistant Surgeon, Croydon General Hospital. \\ Late Surgical Registrar, Charing Cross Hospital.)
}

Of the more usual surgical emergencies none give rise to such anxiety in their treatment as do head injuries. Operative intervention in an unsuitable case may bring about a fatal termination through additional shock when less active treatment would have allowed a recovery. An ill-timed operation is as much to be deprecated as is the failure to recognise a syndrome in which such a line of treatment is immediately essential.

\section{SOME GENERAL PRINCIPLES.}

It has now been repeatedly made clear that the presence or absence of a fractured skull is of little significance compared with the possible damage to the underlying structures, so that the habit of having an X-ray on the way to the ward with its resulting disturbance to an already shocked patient is steadily being replaced by the recognition that other investigations are of infinitely more help. Indeed an X-ray is of no service in an acute case, for depressed fracture practically speaking does not occur in the absence of an open wound and will therefore always be discovered during that careful inspection which should precede the toilet of any scalp wound. On the other hand a linear fracture shown up by the $\mathrm{X}$-ray could only serve to confirm the fact that the original violence had been severe, for it is the disclosure of such a fracture by the appearance of blood or cerebro-spinal fluid from the ear or the nose that indicates the necessity for minimising the risks of infection passing intra-cranially along the path thus established. This is achieved by keeping the area clean and lightly packed with antiseptic solution but avoiding syringing and tight plugging.

A lumbar puncture may well be of the greatest help in the elucidation of a cerebral injury. In the first place the pressure of cerebro-spinal fluid in an index of the intra-cranial tension, and it can definitely be stated that a manometer of $250 \mathrm{~mm}$. of water or thereabouts is an indication of a degree of cerebral compression. In the second place the presence of blood is of paramount importance since it indicates damage to the brain itself or a diffuse subdural hæmorrhage, neither of which conditions respond to operative interference. It will further indicate that resolution will be slow and probably incomplete with unpleasant sequelæ. On the other hand a relatively clear fluid under raised tension combined with evidence of progressive cerebral compression would suggest an extradural hæmorrhage demanding operation. Another principle of help in solving the problem is that the less marked the lucid interval between the states of concussion and compression, the less orderly the progress of irritation followed by paralytic phenomena, the less should one incline towards operation. Finally a patient in deep coma with a falling blood pressure, a rising pulse rate and periodic breathing is no fit subject for decompression. I have mentioned these general principles before going on to the treatment of the classical type of head injury because cases are so frequently seen in which, after hours of the most careful consideration and consultation, decompression has been undertaken with an early post-operative death. When the post-mortem has revealed extensive cerebral injury the surgeon 
has consoled himself by saying that even if the patient had survived the operation he would never have done any good. It should be realised however that an operation which has done no good has almost certainly done harm.

\section{TREATMENT OF THE CLASSICAL TYPE.}

In the treatment of concussion the immediate indication is to put the patient to bed either lying flat or with the foot of the bed raised according to the degree of shock persisting. In view of the fact that urine and fæces may have been passed involuntarily careful cleansing is necessary to avoid the onset of bed sores, whilst the subsequent retention of urine and constipation are treated secundum artem. The patient should be covered with warm blankets but stimulants are to be avoided at this stage. The scalp should be examined for any wound, the treatment of which will be summarised later, and any escape of blood or cerebrospinal fluid from the ear or nose should receive immediate attention.

Should unconsciousness persist lumbar puncture is indicated and in view of the fact that the presence or absence of blood is of importance, it is necessary to perform a clean puncture. The case should be carefully watched with attention to the following points:- the depth of coma as indicated by the patient's reaction to various stimuli should be observed, since a steadily deepening coma with no lucid interval and usually accompanied by a deeply blood-stained cerebro-spinal fluid indicates a severe injury to the brain which will not be benefited by operation. Blood pressure readings should be charted against the pulse rate in order to recognise at the earliest moment the slowing full pulse accompanied by a rising level of blood pressure characteristic of compression. Similarly the respiratory rhythm must be observed for that noisy sterterous breathing which precedes Cheynes-Stokes respiration. Examination of reflexes, of muscle tone and of pupillary abnormalities is of value in providing signs of localised compression and it is therefore inequality of the two sides which gives the important clues.

The patient may at this time show signs of reaction which, in favourable cases, brings about an almost complete return to normality, but which, in severe cases, may proceed to that state of restlessness and excitability that we know as cerebral irritation. He should now be nursed propped up in bed, the room darkened and a minimum of external stimuli allowed to reach him. Sedatives will be required both for restlessness and for headache. Paraldehyde, chloral and bromide can be given - without very conspicuous success-but it is customary to withhold morphia except as a last resort. This state is attributed to cerebral congestion with œdema and excess of cerebro-spinal fluid and in these cases Weed's therapy of dehydration of the brain by hypertonic solutions is indicated, especially when lumbar puncture has shown a comparatively clear fluid under raised pressure. This treatment may be harmful in cases of severe cerebral laceration and of intra-cranial bleeding. The most effective means of producing such a shrinking of the brain is by the intravenous injection, repeated if necessary, of some 50 c.c. of 30 per cent. dextrose. A similar strength of sodium chloride has been recommended but it has been found that a secondary wave of odema follows on account of the immobilisation of the salt in the tissues. A rectal infusion of Io ozs. of Io per cent. solution of magnesium sulphate is well tolerated if given slowly and produces a definite lowering of intra-cranial pressure. So powerful is the effect of such injections that they have been employed to bring out focal signs in cases of coma apparently due to generalised cerebral compression. 
Lumbar puncture is of little therapeutic value in acute head injury since with increased intra-cranial tension it may cause wedging of the medulla into the foramen magnum, while an equally gratifying relief of headache may be obtained with less risk by the hypertonic solution just mentioned. Generalised œdema which does not respond to these measures may require right sub-temporal decompression, and rarely in cases where the general condition of the patient deteriorates steadily and he passes from concussion into a state of generalised cerebral compression, decompression may be considered, but unless an extradural hæmorrhage has escaped diagnosis little but disappointment follows.

\section{TREATMENT OF TRAUMATIC INTRA-CRANIAL HEMORRHAGE.}

The question of traumatic intra-cranial hæmorrhage must now be dealt with. A rupture of the middle meningeal artery or its accompanying veins gives rise to a picture which is well described in text books. There is initial concussion, usually severe, followed by a lucid interval lasting between a half and six hours to be followed in its turn by the orderly onset of paralysis preceded by irritative effects upon the various centres of the brain, determined in order by their distance from the source of the bleeding. If this were the whole story few difficulties would arise, but the classical picture is of uncomplicated extradural hæmorrhage, whereas in practice it is found that violence sufficiently severe to produce this lesion also causes a varying degree of cerebral contusion and laceration which complicates the picture and obscures the indications for operation. For middle meningeal hæmorrhage is a condition of little danger if recognised and treated early. A trephine opening is made over the anterior branch of the vessel, the landmark for which is four centimetres above the zygoma and four centimetres behind the external angular process of the frontal bone; the hæmatoma is evacuated and any obvious bleeding point secured. So successful are the results that the surgeon must be prepared to explore whenever there is reasonable cause to believe that extradural hæmorrhage is occurring, even though the typical syndrome is not present the occurrence from time to time of bilateral hæmorrhage must be remembered.

Sub-dural hæmorrhage is due to a rupture of the cortical vessels or of one of the venous sinuses. In its acute diffuse form it produces compression superimposed upon concussion with little or no lucid interval. The progress of the compression is of such rapidity that its orderly sequence may not be observed. The cerebro-spinal fluid is deeply bloodstained and the fatal issue is not averted by operation. The other form of sub-dural hæmorrhage is the chronic encysted variety occurring after less severe violence and readily amenable to operation, but its delayed onset removes it from the scope of the present article.

\section{TREATMENT OF THE SCALP WOUND.}

There now remains to be considered the treatment of the scalp wound and of any depressed fracture which may be encountered. The area surrounding the wound should be widely shaved; lacerated skin and devitalised tissue excised and the wound washed out to remove all dirt and the depth of the wound carefully explored for any depression. If none is present the wound is loosely stitched to allow adequate room for drainage between the stitches. A one in a thousand solution of flavine is applied as a dressing and an injection both of anti-tetanic 
and anti-gas-gangrene sera given as a routine precautionary measure. Should a depressed fracture be discovered it must be elevated irrespective of symptoms and it is frequently found that the inner table of the skull is more extensively damaged than the outer. An elevator can frequently be introduced beneath the depression by removing a loose piece of bone, or alternatively through a trephine opening made at the edge of the area. It is probably wiser to remove the depressed area entirely so that no fragment of the inner table can be left to predispose to such an unpleasant complication as epilepsy. In any case all loose fragments should be discarded, the dura if intact. should not be opened since in the absence of a sub-dural hæmatoma it is unnecessary and in its presence the danger of infection outweighs the hæmatoma. Following the operation the case is treated according to the nature of the concomitant intra-cranial damage. 